\title{
Arquitectura: una red de significaciones que develan las costumbres y los cambios de una sociedad*
}

\author{
Architecture: A Network of Meanings that Reveal the Customs and \\ Changes of a Society
}

Arquitetura: uma rede de significados que revelam costumes e mudanças de uma sociedade

Recibido el 18 de febrero de 2017. Aceptado el 30 de agosto de 2017

Para citar este artículo:

Agudelo Palacio, Paula Andrea;

Duarte Sepúlveda, Yigan

Alexandra y Gutiérrez Botero,

Manuela (diciembre, 2017)

Arquitectura: una red de

significaciones que develan las

costumbres y los cambios de una

sociedad. Ánfora, 24(43), 109-

136. Universidad Autónoma de

Manizales. ISSN 0121-6538.

\author{
Paula Andrea Agudelo Palacio** \\ Colombia \\ Yigan Alexandra Duarte Sepúlveda*** \\ ombia \\ Manuela Gutiérrez Botero**** \\ Colombia
}

\section{Resumen}

Objetivos: identificar los significados que otorgan los jóvenes a los lugares que habitan y la manera en que interpretan las significaciones de sus antepasados, mediante la lectura de formas arquitectónicas.

\footnotetext{
* Artículo derivado de la investigación "Arquitectura: una significación de la lectura desde las voces de concreto. Presentada por las autoras para optar al título de Licenciadas en Educación Básica con Énfasis en Humanidades y Lengua Castellana. Desarrollado en la institución educativa Rafael J. Mejía del municipio de Sabaneta, (Antioquia, Colombia) entre el segundo semestre de 2015 y el primero del 2016. Se llevó a cabo con estudiantes del grado décimo y con el respaldo (en asesoría) de la institución universitaria Tecnológico de Antioquia, Medellín Colombia.

**Licenciada en Educación Básica con Énfasis en Humanidades y Lengua Castellana. Institución universitaria Tecnológico de Antioquía. Correo electrónico: pauga16@hotmail.com

*** Licenciada en Educación Básica con Énfasis en Humanidades y Lengua Castellana. Institución Universitaria Tecnológico de Antioquia Correo electrónico: ganyi91@yahoo.com.co

**** Licenciada en Educación Básica con Énfasis en Humanidades y Lengua Castellana. Institución universitaria Tecnológico de Antioquia. Correo electrónico: magubo85@hotmail.com
} 
Metodología: a partir del método de Investigación Acción, metodología cualitativa, se acude al Diario Pedagógico y al Diario del Estudiante como instrumentos que permitieron recoger, comparar y seleccionar la información. También se emplearon fotografías y filmaciones para detectar elementos que no se advertían en los registros escritos: gestos y posturas corporales. Se asumió la estructura arquitectónica como texto de lectura a través de su disposición vertical u horizontal, el tamaño, el color y los ornamentos que constituyen elementos de lectura. Resultados: se encontró que los jóvenes significan el objeto arquitectónico a través de sus vivencias y de sus relaciones afectivas; lo asumen como lugar íntimo que les permite liberarse de las máscaras utilizadas en los espacios exteriores y le reconocen como refugio: sus muros delimitan el espacio, aíslan los conflictos externos y proporcionan seguridad. La forma, el tamaño y el color de la estructura arquitectónica se constituyeron en un factor para interpretar las significaciones de antaño, además de ser útil en la comprensión de las costumbres sociales. Conclusiones: los significados de los jóvenes posicionan el lugar que habitan como un modo de escape de lo cotidiano; un espacio donde se logra el reencuentro con la esencia del ser.

Palabras Claves: Arquitectura; Texto; lectura; Significación.

\section{Abstract}

Objective: to identify the meanings given by young people to the places they inhabit and the way they interpret the significance of their ancestors, by reading architectural forms. Methodology: from the method of Research Action, a qualitative methodology, the Pedagogical Journal and the Student's Journal were used as instruments in order to collect, compare and select information. Photographs and films were also used to detect elements that were not able to be detected in written records: body gestures and postures. The architectural structure was added as a reading text through its vertical or horizontal layout, size, color and ornaments that constitute as elements of reading. Results: it was found that young people interpret the architectural object through their experiences and their affective relationships; they assume it as an intimate place which allows them to free themselves from the masks they use outside and recognize it as a refuge: their walls delimit space, isolate external conflicts and provide security. The shape, size and color of the architectural structure became a factor in interpreting the meanings of yesteryear, as well as being useful in understanding social customs. 
Conclusions: young people position a sense of escaping from the everyday in the places that they inhabit; a space where the reunion with the essence of the being is achieved.

Keywords: Architecture; Text; reading; Significance.

\section{Resumo}

Objetivo: identificar os significados que os jovens outorgam aos lugares em que habitam e como eles interpretam os significados de seus antepassados, mediante a leitura de formas arquitetônicas. Metodologia: a partir do método de Pesquisa-Ação, metodologia qualitativa, acudiu-se ao Diário Pedagógico e ao Diário do Estudante como instrumentos que permitiram recolher, comparar e selecionar a informação. Também foram usadas fotografias e filmes para detectar elementos que não foram utilizados nos registros escritos: gestos e posturas corporais. A estrutura arquitetônica foi assumida como texto de leitura através de sua disposição vertical ou horizontal, tamanho, cor e ornamentos que constituem elementos de leitura. Resultados: achouse que os jovens representam o objeto arquitetônico através de suas experiências e suas relações afetivas; Eles o assumem como lugar íntimo que lhes permite se libertar das máscaras usadas nos espaços exteriores e são reconhecidos por eles como refúgio: seus muros delimitam o espaço, isolam os conflitos externos e garantem segurança. A forma, tamanho e cor da estrutura arquitetônica constituíram um fator para interpretar os significados do passado, além de ser uteis para entender os costumes sociais. Conclusões: os significados dos jovens posicionam o lugar que eles habitam como uma forma de fugir da vida cotidiana; um espaço onde se consegue o reencontro com a essência do ser.

Palavras-chave: Arquitetura; texto; leitura; Significado. 


\section{Introducción}

El ser humano se ha servido de los espacios habitables para suplir las necesidades según las circunstancias de cada época. En la edad de piedra, por ejemplo, encontraba resguardo en cavernas para protegerse de las fieras, la intemperie y para reposar en la noche. De este modo, la gruta escarpada se dotaba de significado al transformarse en una especie de refugio que "delimitaba el espacio externo" y se constituía en el principio de un espacio interno, donde el hombre comenzó a asociar la caverna con la seguridad y a descubrir una sensación de intimidad en el interior de los espacios cerrados; a partir de esto, les otorga una significación que dio inicio a la historia de la arquitectura (Eco, 1981).

Con el paso del tiempo se ha resignificado la idea de lugar habitado con apreciaciones que implican no solo protección sino descanso y congregación familiar, deviniendo en objeto fundamental para los individuos. En este sentido, se puede hablar de un vínculo entre el ser humano y el espacio que habita, el cual es evidente en la obra de Richard Sennet (1997) Carne y Piedra. El Cuerpo y la Ciudad en una Civilización Occidental, en la cual el autor expone la época Grecorromana, como un momento histórico en la que el cuerpo humano servía como modelo de suntuosas edificaciones, dispuestas para ser admiradas desde las imágenes y desde el orden visual y geométrico.

La geometría del espacio, entonces, trasmitía disciplina del movimiento corporal, las casas y su construcción eran congruentes con las clases, edades y propiedades de sus habitantes. En una casa, los invitados se consideraban cercanos e importantes para la familia, a partir del lugar y de los espacios a los que accedían. Las residencias revelaban unas líneas de poder (líneas sanguíneas), ángulos rectos, estructuras de formas estrictas, que permitían encontrar seguridad en su interior.

Así mismo se puede hablar de la vivienda como un espacio prescriptor; según Giovanni Klaus Koenig (citado por Eco, 1981), la arquitectura en su función de signo ${ }^{1}$ es incitadora de las prácticas de habitabilidad, pues considera que un signo es un estímulo que influye sobre los comportamientos en determinadas circunstancias. De esta manera, el espacio que sirve como morada adquiere un sentido condicionante como facilitador o delimitador de las funciones sociales; esto, a partir de características como la extensión: no se puede acoger a un gran

\footnotetext{
1. La semiótica ha tenido cierta dificultad en aceptar como signo a la arquitectura, a razón de que esta no tiene como función la comunicación, sino que su fin es de utilidad. No obstante, teóricos como Umberto Eco la analizan desde la fenomenología para otorgarle carácter de signo; esto, a partir de que la relación entre sujeto y objeto arquitectónico ocurre como acto comunicativo sin que esto implique dejar de lado la utilidad del objeto (Eco, 1981).
} 
número de personas en un recinto pequeño, a diferencia de los lugares espaciosos que resultan idóneos para la aglomeración de gentes. Así, el objeto habitado deja de ser solo funcional para pasar a tener implicaciones en la vida del ser humano.

Al respecto, Koenig (1981) y Sennet (1997) exponen la relación del ser humano con el espacio habitado como un vínculo que trasciende la utilidad y se constituye en lo que manifiesta Arias (2013):

Cuando se habla de arquitectura, se habla de una práctica cultural que contiene los rituales, los eventos y las particularidades de la vida de los sujetos en sus espacios, $[\ldots]$ una construcción de la realidad que recopila, integra y escenifica una cultura, una forma de vivir y de concebir la realidad (p. 9).

Sin embargo, esta relación pierde estabilidad puesto que la tendencia natural de las personas al cambio transforma todo lo que les rodea y, por ende, el espacio que moran se transmuta con el paso de los años y adquiere nuevos significados, relegando las connotaciones pasadas. Este suceso trae consigo alteraciones que casi siempre ocasionan tensión entre las nuevas generaciones y las personas mayores, puesto que la innovación de los más jóvenes choca con el instinto de conservación de sus antecesores; Castoriadis, (1983) se refiere al cambio social como una fisura entre lo que ya está instituido y lo que se quiere instituir mediante la transformación.

Castoriadis encuentra el cambio como una grieta que amenaza la solidez de la sociedad, en la medida en que siempre existirán diferentes ópticas con respecto a todo lo que altere la linealidad de un pueblo. Las transformaciones pueden darse de un modo paulatino, asunto que resulta fructífero para la sociedad, pues permite que el individuo no solo asimile el suceso, sino que haga parte del mismo, ya sea desde la confrontación o aprobación. Además, el cambio puede aparecer de forma vertiginosa para constituirse en punto de quiebre entre dos generaciones, por ejemplo, con las modificaciones arquitectónicas por la demolición y construcción de nuevos espacios.

Cuando la arquitectura de una ciudad es el foco del cambio y éste ocurre de un modo abrupto, los significados impregnados en las casas se desploman juntamente con los muros; en su lugar se edifican nuevas viviendas sin dar tiempo a recuperar la esencia de ese vínculo establecido entre los antepasados y sus casas. De este modo, se dificulta la construcción de significaciones para los nuevos espacios, ya que los jóvenes suelen vislumbrarse con la idea de progreso, mientras los mayores se rezagan en anhelos por las épocas pasadas. Por eso, la significación del espacio arquitectónico se debilita y tiende a desaparecer.

De acuerdo con lo anterior, se considera oportuno evocar el postulado de Agudelo (2011), quien concede relevancia, a partir de las ideas de Castoriadis, 
a la necesidad de introducir el papel de las significaciones en la sociedad actual para lograr una mayor comprensión de ésta y del lugar del ser humano en ella. A razón de lo mencionado, se lleva a cabo esta investigación de carácter pedagógico, que busca analizar los significados que otorgan los jóvenes del municipio de Sabaneta (Antioquia, Colombia), a los lugares en que habitan y la manera en que interpretan las significaciones de sus antepasados, mediante la lectura de las estructuras arquitectónicas de su contexto, lo cual se da a través de los elementos físicos de los lugares habitables: color, tamaño, ubicación, forma, ornamentos.

Cabe resaltar que el referido municipio ha sido objeto de constantes modificaciones en el aspecto arquitectónico con diversas posturas y expectativas en sus habitantes; esto, puede ser un factor influyente en la construcción de nuevos significados y en la interpretación de las significaciones instituidas. En este sentido, los jóvenes sabaneteños tendrán la posibilidad de observar el fenómeno de la demolición de las casonas, bajo una óptica de reflexión y análisis acerca del papel que desempeñan ellos en una sociedad que muta y de qué modo se afectan o se benefician en su rol de habitantes.

El presente estudio tiene además la pretensión de aportar fundamentos para que los jóvenes se reconozcan como creadores de significado, inmersos en una sociedad cambiante y como seres humanos facultados para observar, analizar y construir una postura propia con respecto a las modificaciones contextuales. De igual modo, se busca incentivar que los jóvenes se asuman como intérpretes de rasgos de esa "dimensión histórica que implica la existencia de un pasado y una tradición social" (Muñoz, 2003, p. 100), alcanzando así un acercamiento a su historia y una comprensión del papel de sí mismo dentro de ella.

Para alcanzar lo anterior, se presenta la arquitectura como un espacio susceptible de impregnarse de sentido y capaz de evocar lo no tangible o lo no presente, según el ejemplo del templo griego que Heidegger (1958) describe como "El edificio [que] circunda la figura del dios a la que deja alzarse ... mediante el templo está presente el dios, esta presencia del dios es en sí la ampliación y la delimitación del recinto sagrado" (p. 56); por lo tanto, el objeto arquitectónico se consolida en una vía que permite acceder a lo que ya no está presente: épocas pasadas.

La estructura arquitectónica puede ser pensada como un texto que gracias a su simbología y a sus elementos puede ser leído; o como una delimitación de espacio que ofrece fragmentos de historia o indica una función. En este sentido, la disposición vertical u horizontal del espacio, el tamaño, el color y los ornamentos se constituyen en elementos de interpretación que develan rasgos culturales, religiosos, entre otros, y posibilitan el acceso a las significaciones de otras épocas. 
Así mismo, se puede observar la utilidad del lugar a partir de ciertos objetos de los que se sirve a manera de símbolos, por ejemplo, las esculturas con forma angelical que invitan al silencio, las cruces, imágenes religiosas, figuras de mármol, todo trasmite un mensaje: dicho lugar es un campo santo. De igual manera, las colosales estructuras de incomparables vitrales y arcos majestuosos con suntuosos capiteles y atrios espaciosos, cuentan a los transeúntes que ese espacio es un recinto religioso católico. Por lo anterior, se puede asumir la arquitectura como texto en la medida en que permite identificar los matices culturales que conforman la historia de un pueblo, provoca la creación de significados e incita a la reflexión con respecto a los modos de habitar.

En este orden de ideas, el presente estudio se dirige al aula porque resulta ser un espacio idóneo para llevar a cabo este cometido, al entenderse como un lugar de confrontación de saberes y de construcción de conocimiento. Es importante resaltar que investigaciones de este tipo son poco usuales en las escuelas colombianas, quizá porque las instituciones educativas se ven forzadas a enfocarse en conceptos que favorezcan los aprendizajes netamente académicos, aunque esto implique dejar de lado otros aspectos del conocimiento que aportan una variedad de elementos propicios para la consolidación de nuevos saberes.

La relevancia de abordar en el aula este tópico radica en la oportunidad de concientizar al joven de que hace parte de una sociedad

[...] que se engloba, que se ciñe entre las demás, inscrita a todas en una continuidad en la que de alguna manera están presentes los que ya no son, los que quedan por fuera e incluso los que están por nacer. [...] En una palabra, es la unión y la tensión de la sociedad instituyente y la sociedad instituida, de la historia hecha y de la historia que se hace (Castoriadis, 1983, p.11).

Asumir las épocas de antaño como una parte ineludible del presente y la actualidad como un eslabón que se enlaza al mañana, permite que el individuo se sienta artífice de su sociedad en la medida en que analiza, cuestiona y confronta lo establecido para instaurar cambios y conservar lo necesario, sin desconocer que las acciones de hoy repercutirán en las generaciones futuras.

Esta investigación también acoge el interés de la escuela con respecto a la enseñanza y al aprendizaje de saberes conceptuales, estipulados por el Ministerio de Educación Nacional de Colombia (2006), buscando transversalidad entre estos y la temática pertinente. En tal sentido, el ámbito escolar se favorece en el campo de la lectura a partir de la consolidación de la estructura arquitectónica como texto; de este modo, se busca inducir la observación y el análisis para alcanzar una significación de la lectura, que consiste en trascender la idea de 
decodificación como única vía y persigue la intención de abordar el texto desde la interpretación para lograr penetrar en los terrenos de lo inferencial y lo crítico.

Aunque se reconoce que la escuela se ha ocupado de buscar otro tipo de interacción entre texto y estudiante en respuesta a tal necesidad, han surgido diferentes propuestas metodológicas enfocadas en la lectura literaria; por ejemplo, Gonzales y Quesada (2005), Calderón y David (2013), López (2009), entre otros, convocan el arte como una aliada incitadora de saberes, idónea para sensibilizar y relacionar al joven con el texto e inducir en él la idea de una producción propia. Estos autores se direccionan principalmente a partir de las artes escénicas y la plástica, dejando de lado la arquitectura.

En ese contexto, esta investigación encuentra sus motivos en la relevancia de exhibir la arquitectura como un texto que puede ser interpretado para obtener rasgos de la historia de un pueblo o municipio, además, de permitir que los estudiantes construyan una postura propia frente a las situaciones que les afectan en su condición de habitantes. De esta manera, se busca favorecer un encuentro entre la arquitectura desde el punto de vista de lectura de los significados que produce una sociedad y los contenidos del área de Lengua Castellana: los niveles de lectura.

Por lo tanto, el espacio habitado trasciende su utilidad para constituirse en un signo que comunica (Eco, 1981) y que significa a partir de las connotaciones de los habitantes más jóvenes.

\section{Metodología}

El estudio se basó en la metodología cualitativa, que permite abordar el carácter reflexivo de los hechos sociales y observar acontecimientos y percepciones de los sujetos implicados, que se constituyen en protagonistas. Por lo tanto, resultó propicio aplicar el método de Investigación Acción, que hace posible la trasformación social, a partir de la participación de los individuos que se instauran como productores de conocimiento desde la interpretación de un fenómeno. El proceso investigativo tuvo lugar en Sabaneta, un municipio de Colombia ubicado en el valle de Aburrá del departamento de Antioquia.

Sabaneta ha sido objeto de fuertes cambios en los últimos años, su infraestructura se modifica de manera vertiginosa y las grandes casonas son derrocadas para dar paso a las construcciones verticales. En este contexto está ubicada la institución educativa en la cual se llevó a cabo el presente estudio, con estudiantes del grado 10, en un rango de edad entre los 15 y los 17 años 
y residentes del municipio, condición que les permitió realizar aportes de gran estima a este trabajo.

Para recoger la información se hizo uso de dos instrumentos principales, los cuales acuden a la escritura como aliada del proceso investigativo, en la medida en que el código escrito permite recoger información, organizarla, seleccionarla e identificar las debilidades y las fortalezas, fijando sus cimientos en argumentos sólidos y confiables (Vásquez, 2008). Uno de estos instrumentos es el diario pedagógico, el cual es propicio porque:

a través de éste se pueden realizar focalizaciones sucesivas en la problemática que se aborda, sin perder las referencias del contexto [ ...] propicia también el desarrollo de los niveles descriptivos, analítico- explicativo y valorativos del proceso de investigación y de reflexión del docente (Martin y Polar, 1999, p. 23).

El diario pedagógico no se enmarcó en la narración de anécdotas, sino que cumplió un objetivo específico en la recolección de datos establecidos previamente y que apuntaban al hallazgo de información respecto a la construcción de significados e interpretación de antiguas significaciones mediante las estructuras arquitectónicas. Sin embargo, no se dejó de lado los sucesos espontáneos y las manifestaciones que se dieron desde la oralidad y que se consideraron relevantes para el estudio.

El proceso investigativo se dio a partir de cuatro categorías de análisis que surgieron a manera de derrotero para alcanzar los fines propuestos y que, a su vez, hicieron posible organizar la información para ofrecer los hallazgos de forma clara y específica: la generación actual y la significación de los lugares en que habitan, ¿qué implicaciones encuentran los jóvenes en la construcción masiva de viviendas? la arquitectura como texto de lectura e interpretación, transversalidad entre arquitectura y procesos lectores.

El diario pedagógico se enmarcó en el seguimiento de los resultados generados a partir de las mencionadas categorías. Por tal razón no solo era relevante perseguir los datos preestablecidos, sino que también se daba pie a las intervenciones repentinas y a los aportes que surgían en el momento. Por eso, "el diario deja de ser un registro escrito del proceso reflexivo, para convertirse progresivamente en el eje organizador de una autentica investigación profesional” (Martin y Polar, 1999, p. 64).

Igualmente, se resalta la importancia que representó el diario del estudiante como segundo instrumento recolector de información. Propicio en la medida en que los datos que se obtienen son individuales, lo cual hace posible la observación del proceso investigativo de forma detallada, su información es confiable pues el estudiante consigna libremente su posición sin recibir influencia de los 
compañeros. La escritura se constituye en un medio idóneo para la investigación, o en palabras de Carlino (2006), en una herramienta para la solución de los conflictos humanos; esta autora indica que la escritura es útil en el registro de información, como medio de extender la memoria humana, como modo de configurar ideas, ya que "al escribir se trabaja sobre el pensamiento" (p. 9) y se da pie al surgimiento de nuevos conceptos.

El instrumento aludido anteriormente, cumplió con la labor de llevar un registro de las percepciones de los estudiantes con respecto a cada una de las categorías de análisis. Al finalizar la sesión, cada participante apuntaba en su diario las percepciones suscitadas; dichos escritos eran direccionados por interrogantes direccionados al aspecto abordado en cada encuentro, todo ceñido por las categorías de análisis. Para citar un ejemplo se exponen las directrices de la categoría: la generación actual y la significación de los lugares en que habitan: ¿qué utilidad encuentras en el espacio en que habitas, ¿cómo sería el espacio en el que quisieras habitar por largo tiempo?, ¿cómo concibes el espacio en que moras? Así mismo, se brindó la oportunidad de registrar aspectos libres que pudieran no ser tenidos en cuenta por el investigador a cargo.

También se acudió a la fotografía y la filmación, soportes tecnológicos de gran utilidad en procesos de observación, pues reconocen elementos que no se advierten en los registros escritos, como los gestos, las posturas corporales, entre otros.

El campo de estudio se conforma a partir de la lectura de lo que se denomina en este estudio "texto arquitectónico", a través de las formas, los colores, la disposición espacial y los ornamentos. Como componente práctico se emplea el taller, entendido éste como un medio que permite la interacción directa entre estudiante y objeto de estudio, de aplicación flexible que tiene en consideración los posibles gustos y saberes de los jóvenes. El taller fue compuesto por estrategias como el cuestionario de preguntas abiertas, con el cual se dio inicio al proceso investigativo, mediante el mismo se buscó conocer las ideas previas de los jóvenes con respecto al "texto arquitectónico" y al concepto que tienen de la lectura. 


\section{Tabla 1. Formato del cuestionario}

\section{Cuestionario de preguntas abiertas}

\begin{tabular}{l}
\hline Conceptos: \\
\hline ¿Qué es la \\
arquitectura? \\
\hline $\begin{array}{l}\text { Define tu idea } \\
\text { de texto }\end{array}$ \\
\hline ¿Qué es lectura? \\
\hline ¿Qué entiendes \\
por significado?
\end{tabular}

Fuente: elaboración propia

También se hizo uso del análisis documental con una aplicación lúdica, con una composición literaria, salidas pedagógicas, fotografías, exposiciones de retratos, construcción textual y conversatorio. Finalmente, se utilizó una rejilla de sistematización que sirvió como instrumento para el análisis, la categorización y el contraste de los datos obtenidos de las diferentes fuentes: diario pedagógico, diario del estudiante, taller y soportes tecnológicos. A continuación, se presenta el formato de la misma:

\section{Tabla 2. Rejilla de sistematización}

\begin{tabular}{|c|c|c|c|}
\hline Conceptos & $\begin{array}{l}\text { Unidad de análisis } \\
\text { diario docente }\end{array}$ & $\begin{array}{l}\text { Unidad de análisis } \\
\text { diario estudiante }\end{array}$ & $\begin{array}{l}\text { Unidad de análisis } \\
\text { soporte tecnológico }\end{array}$ \\
\hline $\begin{array}{c}\text { Interacción joven } \\
\text { espacio }\end{array}$ & & & \\
\hline $\begin{array}{l}\text { Grado de impor- } \\
\text { tancia del objeto } \\
\text { arquitectónico }\end{array}$ & & & \\
\hline
\end{tabular}


Para efectos de mayor comprensión, esta investigación se valió de las siguientes siglas: diario pedagógico:

DP (Se agregará una letra que representa la inicial del apellido del investigador: $D, G, A)$

Diario del estudiante: DE

Registro fílmico: RFL

Registro audio: RA

Registro fotográfico: RFT

En el siguiente ítem se exponen los hallazgos a partir de la aplicación de los talleres y de los registros en los diarios y/o en los soportes tecnológicos, los cuales están encaminados al logro del objetivo principal: Analizar los significados que otorgan los jóvenes a los lugares en que habitan y la manera en que interpretan las significaciones de sus antepasados mediante la lectura de las estructuras arquitectónicas, para acercarse a la comprensión de su sociedad.

Ahora, como el objetivo general no se limitó al análisis de los significados que otorgan los jóvenes a los espacios en que habitan, sino que también buscó analizar la forma en que se interpretan las significaciones de antaño, se valió de la lectura de las estructuras arquitectónicas; es decir, fue necesario presentar la arquitectura en virtud de texto y la lectura como una interpretación que puede prescindir del código escrito y aun así trasmitir un mensaje.

Por lo cual, este estudio segmentó la información para analizarla de acuerdo con cuatro categorías que obedecen a un orden lógico para la exposición de los resultados; por lo tanto, cada una de ellas se encuentra reflejada en el objetivo principal.

\section{Resultados}

El estudio determinó las siguientes categorías: la primera, la generación actual y la significación de sus lugares habitables, se enfoca en las primeras líneas del citado objetivo; de igual modo, la segunda categoría: qué implicaciones encuentran los jóvenes en la construcción masiva de viviendas, se constituye en una forma de profundizar en esas significaciones, pues al indagar los modos en que los jóvenes perciben el acelere de la construcción se obtiene la importancia que suponen los espacios arquitectónicos, desde su perspectiva.

La tercera categoría: las estructuras arquitectónicas como texto de lectura e interpretación, buscando que los jóvenes asuman el "texto arquitectónico" surgió como una forma de acceder a las significaciones de sus antepasados para acercarse a una comprensión de la sociedad. Esta categoría se ubica desde la lectura con el 
uso de la observación y el análisis, de la inducción y la deducción que permiten la construcción de hipótesis; así, se evidenció una cuarta categoría: transversalidad entre arquitectura y procesos lectores, que posibilita una idea más amplia del tex to y de la lectura, en este caso el "texto arquitectónico"

A partir de las anteriores categorías se obtienen algunos cuestionamientos que surgen desde los intereses de los estudiantes o a juicio de las investigadoras, tales preguntas se consolidan como escalones que permiten acceder a los objetivos. De este modo, la primera categoría: la generación actual y la significación de sus lugares habitables, hace posible abordar la siguiente pregunta: ¿qué importancia supone el espacio habitable en la vida del joven actual? De la categoría: qué implicaciones encuentran los jóvenes en la construcción masiva de viviendas, se desprende un interrogante: ¿̨ómo asumen los jóvenes la demolición de las casonas? En la tercera categoría: Las estructuras arquitectónicas como texto de lectura e interpretación, surgen tres cuestionamientos: ¿Qué apreciación tienen los jóvenes con respecto a la arquitectura como texto?, ¿qué actitud asumen con respecto a los significados construidos por sus antepasados y de qué manera puede influir en la comprensión de su contexto? En la cuarta y última categoría: transversalidad entre arquitectura y procesos lectores, el cuestionamiento es: ¿̨cómo conciben los estudiantes la vinculación de la arquitectura y la lectura?

\section{La generación actual y la significación de sus lugares habitables}

El ser humano ha logrado establecer un vínculo con el arte de la construcción, gracias a que, entre todas las formas de arte, la arquitectura es la única que permite ser poseída y penetrada al ofrecerse como morada. El hombre no solo aprecia la creación arquitectónica, sino que se sirve de ella y al encontrarla más inmediata que las demás artes descubre la importancia que esta supone para su vida, la dota de una significación que se inscribe en "esa red cambiante de significados que configura modos de comportamiento y creencias” (Arribas, 2008, p. 106).

Para exponer las significaciones actuales conferidas a las viviendas, resultado de este estudio, se aborda la pregunta que se deriva de la presente categoría ¿qué importancia supone el espacio habitado en la vida del joven actual?, que resulta conveniente en la medida en que la creación de significados tiene lugar, a partir de la importancia que le otorga el sujeto al objeto habitado. Así lo expone Eco, (1981) citando a Vico, al referirse al hombre de la edad de piedra, que llega a significar la caverna como refugio, a partir de la utilidad que ésta le presta, pues advierte la importancia de ese lugar: "se da cuenta de la amplitud de la bóveda es el límite de un espacio externo, que ha quedado fuera con el agua y el 
viento" (Eco, 1981, p. 253). En este sentido, es oportuno analizar la relevancia que conceden los jóvenes sabaneteños a los espacios que habitan.

Así, la casa adquiere importancia en la medida en que trasciende la idea de utilidad para consolidarse en el lugar responsable de congregar a la familia, un escenario en el que se desarrollan diferentes situaciones:

\begin{abstract}
“Describir mi casa sería algo muy complicado y difícil de entender [...] Allí no solo está esa parte positiva, si no también ciertos sentimientos o momentos negativos, momentos de soledad, tristeza y amargura; será tal vez el lugar donde menos deseo estar y en el que más tiempo estoy. Por otro lado, siendo contradictorio, es donde sé que puedo ser yo, estar en casa es descansar y salir del mundo exterior" (tomado del DE5); "exhiben la casa como [...] un lugar donde se desarrollan los conflictos, pero también se resuelven en compañía de la familia, o por lo menos resulta más sencillo sobrellevar las dificultades" (tomado del DPA)
\end{abstract}

En la misma perspectiva, al referirse al templo Heidegger (1958) expresa, que se trata de un espacio que:

construye y congrega simultáneamente en torno suyo la unidad de aquellas vías y relaciones en las cuales el nacimiento y la muerte, la desdicha y la felicidad, la perseverancia y la ruina, toman la forma y el curso de la vida humana (p. 57).

Son pues diversos los factores por los cuales el lugar que sirve de vivienda cobra importancia en la vida del joven: la interacción que se genera en su interior, la compañía de sus seres queridos y la confrontación y posible solución de conflictos, se constituyen en razones que ocasionan un interés por la morada. Así mismo, es importante resaltar la relevancia que adquieren los cuartos: "Mi habitación: es el lugar donde todo cobra vida, cuando entro y siento mi olor y la presencia de mis cosas. Cuando me acuesto en mi cama ella empieza a liberar todo mi estrés, es el lugar donde cada día renacen mis esperanzas” (tomado del $\mathrm{DE} 4)$.

Los jóvenes encuentran propiedad en el espacio que designan para descansar; allí donde cada objeto se impregna de su presencia. Por lo anterior, se puede pensar en la sensación que imagina Vico (citado por Eco, 1981), al recrear el pensamiento del hombre de la edad de piedra, que se repliega entre la gruta rodeado de la sensación de seguridad que ésta le suministraba, el hombre pudiera "evocar nostalgias uterinas" al sentirse protegido; así la habitación y la caverna adquieren relevancia.

De esta manera, queda develada la importancia que suponen los espacios para los jóvenes en la actualidad y se evidencian los significados que otorga la 
generación actual a los lugares habitables: "Ahí, en mi habitación, es el lugar donde me refugio cuando quiero rendirme, ella no habla, pero me escucha y a su vez nos conectamos y comparto mi estado sin necesidad de hablarle" (tomado del DE3). Es notorio el vínculo existente entre los jóvenes y sus lugares, ante lo cual se puede deducir la creación de significados: la casa trasciende al espacio físico para transformarse en un símbolo de confort y calidez, pero sobre todo se torna en una representación de lo no tangible; es decir, de las emociones que se gestan en el interior de los espacios cerrados, de los sentimientos que brotan y de los que se marchitan, de las palabras expresadas y de aquellas que mueren en la garganta.

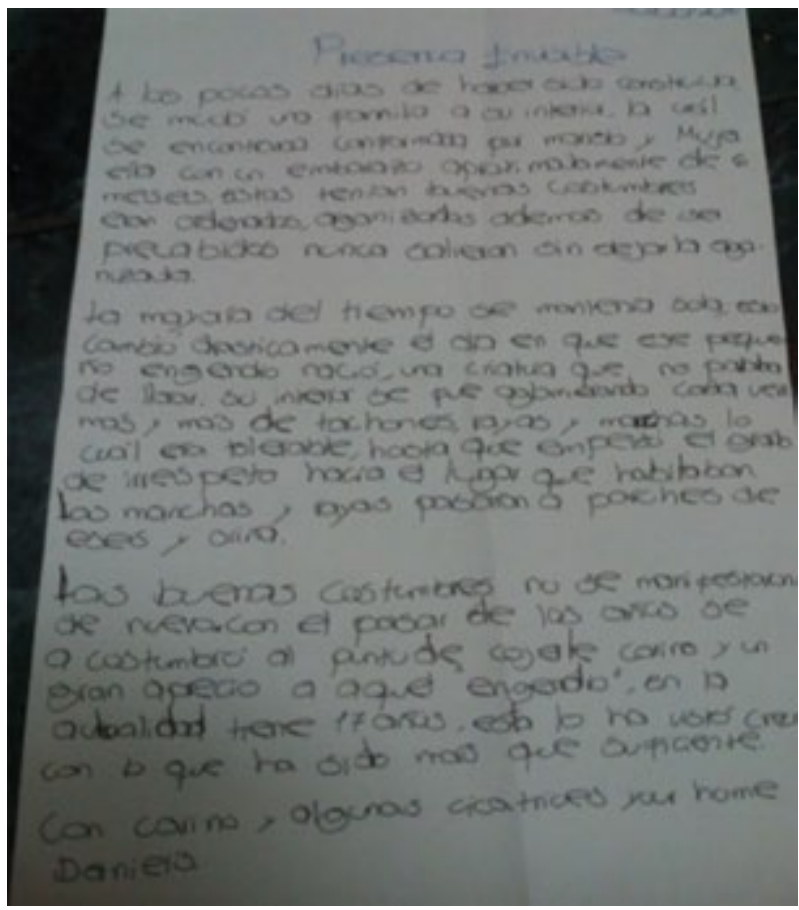

Fuente: DE3

De este modo, la arquitectura deja de ser solo un espacio funcional para convertirse en una obra con connotaciones simbólicas, susceptibles de ser 
interpretadas y resignificadas "un espacio vivido, que trasciende toda delimitación homogénea o matemática" Schulz (2008).

La casa es el cuerpo abierto de un amante

La casa es el puerto y la barca

En la cual viajamos cada noche a la isla de los sueños

La casa tiene fallas, cicatrices, accidentes del tiempo

Arrugas prematuras, pero la casa también fue joven

Tuvo blanca túnica y zapatos de verano

Llevando una tiara de rombos se abanica con los juncos

En su vientre pasa todo: los juegos, el piano, las palabras,

Las risas, los maullidos...

El silencio azul e inquieto de las noches lunares (Fuente: ejercicio de personificación de vivienda).

Es importante mencionar que la generación actual otorga significado a los espacios en que habita a partir de las vivencias que se desarrollan en el interior de estos y de los vínculos que establecen con sus congéneres, ya que, el aposento se instaura como un espacio íntimo que brinda la oportunidad de dejar de lado las posibles máscaras que se emplean fuera de la morada, por consiguiente, la casa se asemeja a un refugio en la medida en que sus muros delimitan el espacio, aislando los conflictos externos y proporcionando un lugar de seguridad para el individuo.

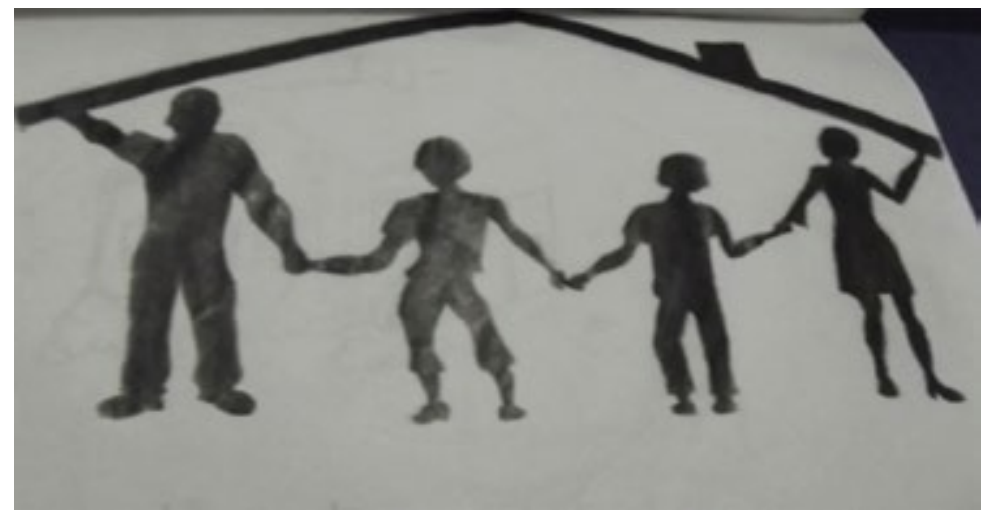

Fuente: tomada del DE5 
La estructura arquitectónica, entonces, adquiere significado en la época actual: refugio, cobijo, intimidad, zona de confianza, seguridad. De este modo, el joven se reconoce como parte de una colectividad creadora de significados, lo cual hace posible el empoderamiento de una postura propia frente a los distintos sucesos que tienen lugar en una sociedad.

\section{Implicaciones que encuentran los jóvenes en la construcción masiva de viviendas}

Es evidente el fenómeno de la construcción masiva en el municipio de Sabaneta (Antioquia, Colombia) con implicaciones para los jóvenes. Es importante resaltar la relevancia que tiene la actual generación en el espacio que habita y la forma en que ello se constituye en el eje de las significaciones. El estudio de la presente categoría desglosa una pregunta necesaria que hace posible ampliar el análisis de las significaciones que otorgan los jóvenes a los lugares en que viven: ¿cómo asumen los jóvenes la demolición de las casonas?

Si bien es cierto que los cambios son inherentes al ser humano no siempre pueden pensarse en términos positivos, en casos puntuales como el que nos compete las implicaciones se traducen en trastornos de habitabilidad. Así lo expresa Jurado (2003) quien afirma que uno de los factores que generan "otros modos de estar juntos" son las modificaciones que sufre una ciudad en sus estructuras arquitectónicas.

En este sentido, la investigación descubre apreciaciones que dan cuenta del sin sabor de los jóvenes respecto a este tipo de sucesos: "Agonizando Que tristeza no crees. - ¿porque dices eso? -es que no lo ves, he vivido más de 100 años y ahora por una administración inmunda acabe destruida en diez minutos, he provocado sonrisas en muchas familias, pero ahora ya no me necesitan" (tomado del RFL, durante un ejercicio de personificación). "La mayoría de los estudiantes coinciden en que lo preocupante de las transformaciones de las viviendas coloniales, además de ser convertidas en establecimientos de comercio, es la pérdida de los espacios rurales, la tradición, el sentido acogedor, tranquilo y familiar" (tomado del DPG).

A partir del anterior fragmento se puede evidenciar que una de las implicaciones de la construcción vertiginosa es "la perdida de los espacios rurales" lo cual resulta, a juicio de los estudiantes, muy lamentable, "era una laguna donde los niños de Sabaneta jugaban... ahora es una urbanización abierta, bastante fría y húmeda" (tomado del RFL).

Los jóvenes encuentran estos cambios como algo arbitrario y de poco beneficio, que difiere en todo sentido de la postura que tienen Paniagua y Roldan (2015), quienes otorgan a la arquitectura un carácter existencial, en la medida 
en que hace posible que el ser humano encuentre la razón de su existencia: habitar. El ser humano pertenece a un lugar determinado gracias al espacio en el que mora y al significado que construyen desde su rol como habitante; pero el fenómeno de la acelerada edificación vertical no tiene en consideración las implicaciones que esto suscita.

Para los jóvenes sabaneteños las consecuencias del mencionado fenómeno tienen colosales dimensiones que afectan la forma de vida del municipio: "expresiones y palabras posicionan a Sabaneta como un municipio rodeado de edificios... construcciones que según muchos acabaron con las mejores zonas de esparcimiento y tranquilidad" (tomado del DPD) "Camino por un edificio más de los que hay en Sabaneta y los meten en cualquier parte" (tomado del DE4); "No solo desaparecen las casas coloniales, también se aniquilan las zonas verdes" (tomado del DE5).Una de las secuelas de mayor peso, a juicio de los jóvenes, es la arbitrariedad que se comete contra las zonas verdes en nombre del progreso: "Calle nueva fue construido sobre un gran paisaje" (tomado del DE3)

\section{Ilustración 3. Diario de Estudiante, 3}

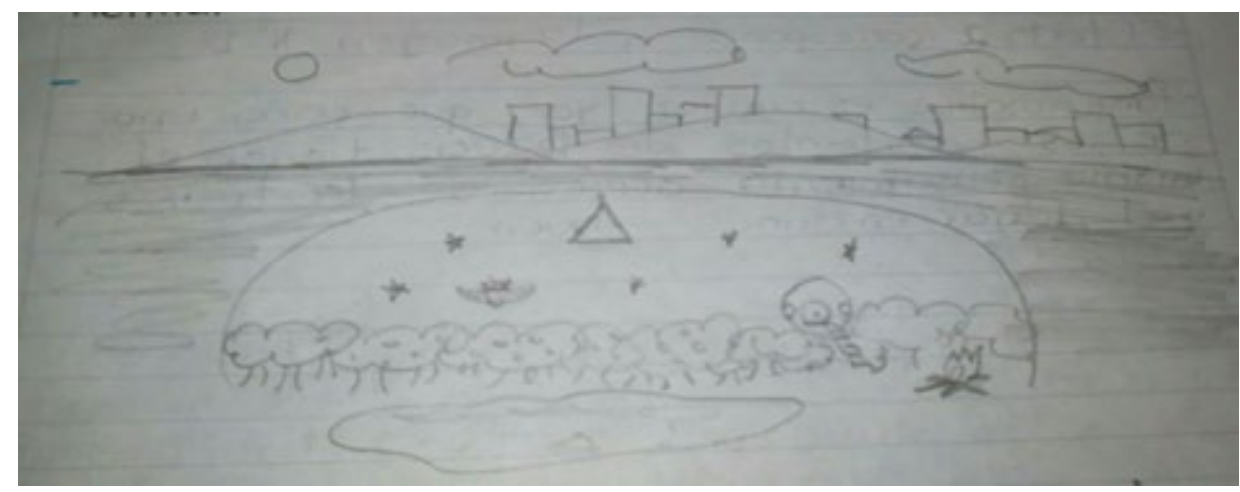

\section{Fuente: tomada del DE3}

La anterior ilustración expone la idea de posicionar el cemento sobre los paisajes. De igual modo, los jóvenes encuentran la demolición de las casas coloniales como un asunto lamentable que convendría atenderlo de otra forma: "Las casas antiguas deberían restaurarse sin ser modificadas para que no se altere la historia, pueden servir como casa o como museo" (tomado del DPA). De ahí que se pueda pensar en el anhelo de los estudiantes de conservar las significaciones impresas en las estructuras arquitectónicas; también traducen 
este asunto de la demolición en el factor permisivo de la construcción masiva, el cual trae consigo otra consecuencia: "Me gustaría que Sabaneta fuera más grande porque hay demasiados edificios y hay sobrepoblación” (tomado del DE4).

Y en la misma línea otro testimonio indica que "El municipio de Sabaneta ha crecido mucho en la infraestructura, por ende, ahora tiene más habitantes, tantos que ya es imposible conocerlos a todos" (tomado $\operatorname{del} R A$ ). De acuerdo con Álvarez (2016) el municipio de Sabaneta, (Antioquia, Colombia) cuenta con 50.000 habitantes, pero según los registros del municipio en tres años vivirán en Sabaneta 100.000 personas, gracias a torres de hasta 40 metros que invadieron sus montañas.

Como se mencionó anteriormente, las dos primeras categorías se centraron en los significados que otorgan los jóvenes a los lugares que habitan, lo cual develó que las construcciones arquitectónicas no solo resultaron interesantes por pertenecer al contexto del estudiante, sino porque permiten una forma de interpretar los cambios sociales de los últimos años en el municipio más pequeño de Colombia, Sabaneta, (Antioquia). Estas son razones que engrosan esas significaciones con las que los jóvenes impregnan sus moradas.

\section{Las estructuras arquitectónicas como texto de lectura e interpretación}

Se da por sentado el hecho de que los jóvenes se asumen como creadores de significado, a partir de la importancia que otorgan a los lugares que habitan, al reconocer en la cotidianidad del cemento y del ladrillo algo más que la funcionalidad del objeto, se reestructura el concepto de vivienda, permitiendo de esta forma la presentación de la arquitectura como texto de lectura e interpretación. La primera pregunta que se desglosa de esta categoría: ¿Qué apreciación tienen los jóvenes con respecto a la arquitectura como texto?, ello permite ubicar los resultados en el escenario educativo.

Aunque este estudio logró conocer las significaciones que los jóvenes sabaneteños otorgan a los lugares en que habitan, entender la arquitectura como texto se dio de forma gradual. Inicialmente los estudiantes se mostraban escépticos, manifestando expresiones como: “De ninguna manera, ¿cómo se va a poder leer algo que no tiene letras?! ¡Eso es muy raro! (tomado del diario del DE1) "No es posible ese tipo de lecturas" (tomado del D E 2). No obstante, cuando descubrieron que la estructura arquitectónica es un texto que, aunque prescinde de grafías trasmite un mensaje, se mostraron interesados, lo cual es el primer paso para visualizar la lectura como una forma de reinterpretar el mundo y forjar otras realidades. De esta manera, empiezan a advertir que leer es un ejercicio que trasciende la distracción para consolidarse en una vía de 
comunicación pedagógica influyente en el desarrollo de diversas competencias, necesarias en la construcción de saberes (Ministerio de Educación Nacional, 2006).

Mediante la implementación de los talleres, se encontró respuesta para la pregunta: ¿de qué manera interpretan los jóvenes las significaciones de sus antepasados? Los estudiantes descubrieron que era posible leer rasgos de las significaciones de antaño, conservados en las estructuras arquitectónicas, a través de los colores, las formas, el tamaño y los ornamentos que se consolidaron en elementos sutiles al momento de interpretar el texto. Según Calvino (1999)

La ciudad no cuenta su pasado, lo contiene como las líneas de una mano, escrito en las esquinas de las calles, en las rejas de las ventanas, en los pasamanos de las escaleras, en las antenas de los pararrayos, en las astas de las banderas [ ...] “(p. 11).

Los jóvenes se acercaron al texto arquitectónico para leer la historia de su pueblo, para evocar las significaciones de antaño: "Entre los tesoros arquitectónicos podemos encontrar un hermoso altar de una virgen típica de la cultura católica que da muestra de su religión, también el amplio jardín en frente de la casa y más adelante un disimulado cercado que da un ambiente más seguro y muestra que la gente que allí vive puede pasar largas horas en casa" (tomado del DE 2). Tal como lo expresa Arribas (2008) "la mayoría de los significados están instituidos, son pautas de conducta familiares o establecidas que se aceptan como parte estructuradora de una cultura" (p.106).

"En el exterior de la vivienda resalta sus dos enormes ventanas de hermosa madera pintada de color negro, un alto corredor con las típicas baldosas de estilo clásico. Las materas que cuelgan bajo el hermoso y alto techo dan el último toque majestuoso de lo que es un sublime ejemplo de la arquitectura colonial. En el interior de la vivienda hay objetos que para nosotros crean un ambiente antiguo, clásico y un poco de pueblo, pero para ellos en el pasado significó la modernidad de ese entonces" (tomado del DE 3). 


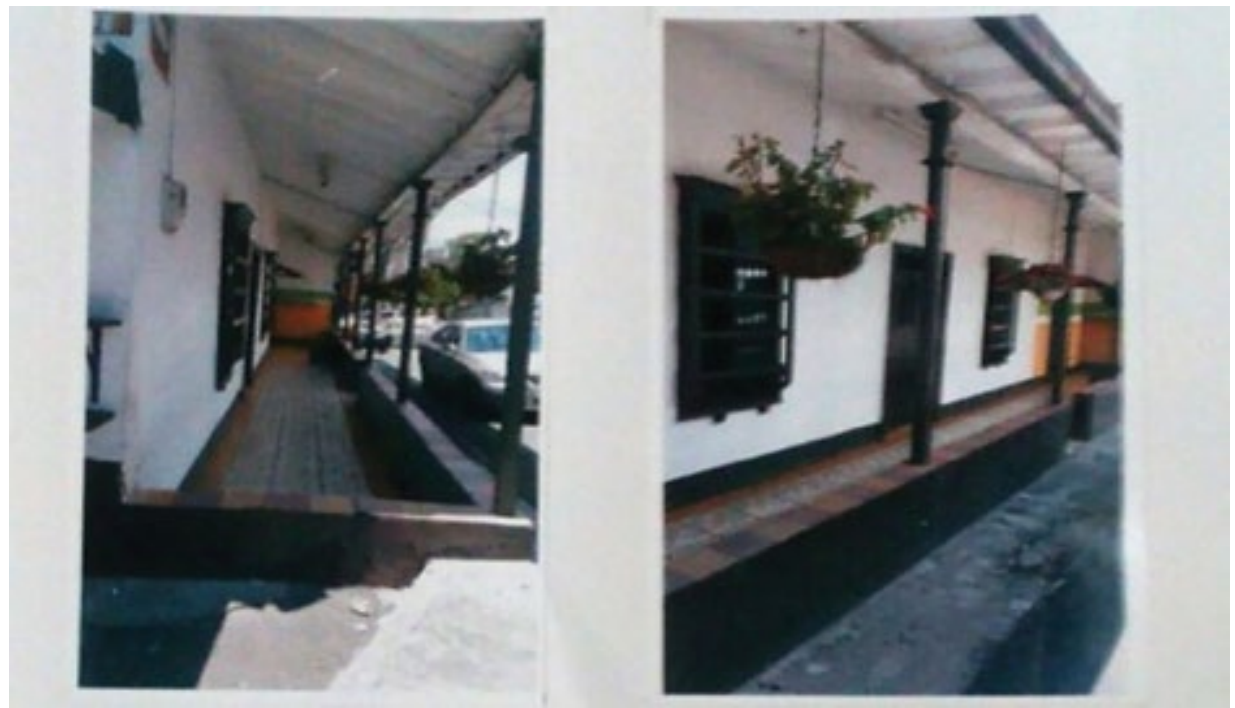

Fuente: Espacios arquitectónicos interiores

Frente a lo anterior, esta investigación encontró que la estructura arquitectónica al ser asumida como texto, se consolida como vía para acceder a ciertos rasgos de las significaciones “instituidas”, lo cual permite abordar la tercera pregunta: ¿De qué manera influye en la comprensión del contexto las interpretaciones de las significaciones de antaño?

Según Arribas (2008), a partir de las ideas de Castoriadis, menciona que los significados instituidos otorgan unidad a la sociedad. En este sentido, las significaciones se consolidan como un vínculo entre los individuos que pertenecen a un determinado lugar y se instauran como parte de la identidad de una comunidad. Por lo cual, acceder a las estructuras arquitectónicas como medio que permite interpretar los significados que se conservan en estos espacios, hace posible que el joven comprenda ciertos aspectos de su sociedad y de la sociedad que le precede. Para citar un ejemplo, se retoman las palabras consignadas en el DE2: "el amplio jardín en frente de la casa y más adelante un disimulado cercado que da un ambiente más seguro y muestra que la gente que allí vive puede pasar largas horas en casa”. Para este estudiante, el prolongado espacio de la vivienda proporciona un lugar idóneo para el esparcimiento y la tranquilidad, que no interviene en la comunión familiar, ya que los habitantes "pueden pasar largas horas en la casa”. A diferencia de las viviendas modernas: "los apartamentos ya 
son muy pequeños, uno se aburre mucho y por eso tiene que salir a distraerse pasando menos tiempo con la familia” (DE3).

\section{Foto 2. Transformaciones arquitectónicas de viviendas}
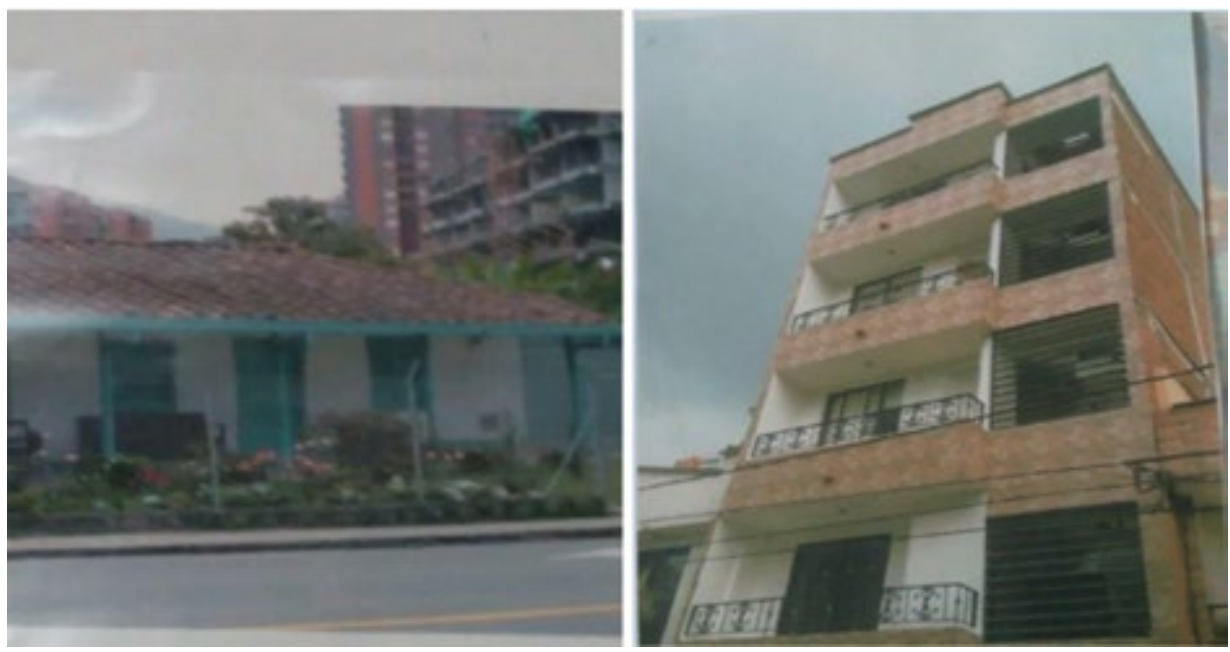

Fuente: tomada del RFT

Así pues, es evidente que el joven comienza a cuestionar los sucesos que ocurren en su contexto y se acerca a una comprensión de éste en la medida en que lee la estructura arquitectónica y analiza las implicaciones de estos espacios en los modos de habitar: "las casas modernas y los edificios deberían tener más espacio y no ser tan estrechas, porque no permiten que vivan las familias grandes" (DE3); "Antes casi todas las casas eran de una sola planta, de colores vivos y en el atrio ponían imágenes religiosas, también colocaban materas, ahora los edificios son de un solo tono y las casas divididas por varios pisos, para que puedan vivir distintas familias” (DE5). Según esto, el joven se acerca al objeto arquitectónico y al descubrir su significación, encuentra coherentes las costumbres y las creencias de la sociedad, lo cual le permite comprender su lugar en ella (Agudelo, 2011).

En este sentido, los jóvenes entienden el espacio que habitan como un factor que refleja rasgos de la conformación familiar: los antepasados tuvieron familias numerosas y la familia contemporánea ha reducido la cantidad de hijos y la posibilidad de convivir con otros familiares: abuelos, tíos, primos entre otros, 
coartando la posibilidad de interactuar de forma continua con los parientes: "los niños de otras épocas tenían muchos hermanitos y hasta vivían con sus primos, no tenían necesidad de jugar en las canchas o calles pues sus casas eran grandes y con jardines y solares. Los niños de la actualidad no pueden ni jugar en los apartamentos les toca desplazarse a otros lugares" (DE5) "La comprensión tiene que ver con la búsqueda y reconstrucción del significado" (Ministerio de Educación Nacional [MEN], 2006, p. 26).

Lo expuesto anteriormente muestra la arquitectura como una forma de interpretación y comprensión de la sociedad cuando ésta es asumida como texto.

Ahora bien, los fenómenos que suceden en una sociedad pueden constituirse en un asunto que interese a todos los individuos; sin embargo, se puede pensar que los más jóvenes no toman parte en los asuntos de la sociedad; esta falsa percepción, empero, obedece al escaso manejo de estas temáticas en el aula de clase, negando así la posibilidad de que el joven lea, interprete y analice las situaciones que le competen para poder construir una postura propia. Por eso, el presente estudio se realizó en el aula de clase, buscando una transversalidad entre arquitectura y lectura.

\section{Transversalidad entre arquitectura y procesos lectores}

Si bien es cierto que existe una complicidad entre la escuela y el arte que busca favorecer el proceso lector o persigue un acercamiento entre estudiantes y lectura literaria, no es muy común la relación escuela-arquitectura. No obstante, el presente estudio encontró su lugar en las estructuras arquitectónicas y se desarrolló en la escuela, con la apuesta de acoger la arquitectura como texto que permitiera una lectura de índole social que beneficiara los procesos lectores, estableciendo así transversalidad entre ambas.

Específicamente en este punto, esta investigación encontró los siguientes resultados: en primer lugar, se abordará el cuestionamiento ¿̇cómo conciben los estudiantes este vínculo? : "me parece bueno que nos ayuden en estas clases a despertar más el interés por la lectura" (tomado del RA); "leer ese tipo de textos nos permite hacer preguntas que nos sirven para comprender mejor todo lo que leamos" (tomado del DE 3); "le encuentro mucho sentido a estos ejercicios que ayudan a la comprensión lectora pues me permiten analizar y pensar" (tomado del DE4). Así, el aula se constituye en un espacio que lleva a cabo lo que enfatiza el MEN (2006) al resaltar la necesidad de abordar los diversos sistemas simbólicos $^{2}$ en las prácticas pedagógicas para brindar posibilidades de lectura e

2.Los sistemas simbólicos son creados por las comunidades humanas para conformar sentidos y para comunicarlos: la música, los gestos, la escritura, la pintura, la escultura, entre otras opciones (MEN, 206, p. 20). 
interpretación que permitan al estudiante establecer relaciones entre concepto y realidad.

Este estudio presentó, entonces, la lectura como una interpretación que, si bien depende en un primer momento del código escrito, se hace necesario que trascienda lo literal para lograr descifrar las analogías, hacer uso de la deducción y de la inducción que brindan al lector datos reveladores en la construcción de la historia o de la información que muestra el texto. En este sentido, la arquitectura como texto permitió que el lector se valiera de ornamentos, colores, formas y tamaños, que hicieron posible deducir rasgos de las significaciones, alcanzando de este modo un "reconocimiento de las estructuras arquitectónicas de su municipio como objetos de análisis" (tomado del DPG). Lo anterior hace evidente lo que expresa Heidegger (1958), al referirse a la obra de arte como algo que trasciende la idea de cosa gracias a su capacidad de ser alegoría y símbolo.

Así mismo, es importante que el lector elabore hipótesis a medida que avanza en la lectura y que se sumerja en ella para obtener comprensión; ello requiere aguzar los sentidos para encontrar lo que a simple vista no se ve y analizar las implicaciones de lo que suscita el código escrito o el texto que prescinde de grafías. A partir de lo mencionado, esta investigación muestra que "Los estudiantes realizaron una lectura con tintes críticos, mediante la comparación entre las estructuras de las casas coloniales y de las viviendas modernas, logrando establecer relaciones de semejanza y diferencia entre estos" (tomado del DPA). Uno de los beneficios de realizar este estudio en el aula, fue el hecho de que el estudiante podía interactuar de forma directa con el texto y participar activamente desde sus vivencias como habitante; esto hizo posible lo que plantea Larrosa (2003): conseguir una experiencia individual a través de las implicaciones de la lectura en la vida del sujeto permitiéndole consolidar lazos entre sus vivencias y el texto.

De acuerdo con los Estándares Básicos de Lengua Castellana (2006), la arquitectura en su calidad de sistema simbólico resulta propicia para habilitar la comprensión y la producción, procesos que requieren de actividad cognitiva tales como el análisis, la abstracción, la síntesis, la inferencia, la deducción, la inducción, la comparación y la asociación. Llevar al aula esta propuesta pedagógica ayuda a que los estudiantes potencialicen sus procesos lectores y accedan a herramientas que les permitan la interpretación del contexto, el análisis del entorno y la comprensión de lo propio. 


\section{Conclusiones}

El ser humano tiene la capacidad no solo de crear significado, sino de sentar estas creaciones sobre las significaciones "instituidas". Si bien es cierto que los jóvenes asumen su vivienda como refugio o lugar íntimo que proporciona seguridad, estas declaraciones no se pueden pensar en términos de innovación, pues el espacio en su función de morada ha sido relacionado con la sensación de seguridad desde la edad de piedra.

Ahora bien, el asunto a resaltar es que los jóvenes descubren en su vivienda un espacio que les brinda la oportunidad de ser auténticos, lo cual se traduce en una forma de privilegio en épocas como la actual, en la que las personas se ocupan más de exhibir que de ser. De ahí que la casa se haya consolidado como el lugar donde se pueden desprender de las máscaras a las que acuden en la búsqueda de aprobación.

La creación de significados surge a partir de la manera en que la persona se vale del espacio habitado para suplir las necesidades que trae consigo cada momento de la historia. De este modo, el individuo de la edad de piedra encontró a través de la caverna un medio de supervivencia, a diferencia de lo esperado en la época Grecorromana, en la que las estructuras arquitectónicas perseguían el ideal de fascinar y, a su vez, buscaban trasmitir disciplina del movimiento corporal (Sennet, 1997), lo cual era propio de una civilización que necesitaba admiración y respeto.

En la actualidad los jóvenes contemplan otras necesidades, sin desconocer la seguridad que proporciona el espacio que habitan, como la intimidad, la congregación familiar y las vivencias. Lo que se requiere hallar en el interior de la morada es la ocasión de ser, el disfrute de ese espacio donde es posible desplegar la personalidad, dejando de lado las apariencias. En este orden de ideas, se puede pensar el significado como una creación que surge a partir de la importancia que se le otorga al objeto, que se mide en términos de solución de una necesidad.

A juicio de Eco (1981) el objeto promueve cierta utilidad y significa, a la vez, esa forma particular de uso; este autor emplea el ejemplo de una cuchara al mostrarla como un utensilio que suscita cierto modo de comer enmarcado en determinados usos sociales. Dicho objeto no adquiere igual significación en contextos donde lo propio es comer con las manos o sorber directamente de la vasija. Frente a esto, se puede decir que Eco considera que las significaciones surgen en la medida en que el objeto suple una necesidad particular de un determinado contexto, de igual forma, expone la caverna como un espacio que impulsa la idea de refugio y, de la misma manera, trasmite la existencia de una posible función. 
A partir de esta postura se reflexiona sobre otra función que encuentra el joven sabaneteño en el lugar donde reside, teniendo en cuenta el fenómeno de transformación arquitectónica en su contexto, la sobrepoblación, y la conversión del municipio en urbe, se comprende no solo la intimidad que supone la vivienda, sino la necesidad de encontrar ocasión para comportarse de forma original.

Este estudio también concluye que el objeto arquitectónico se carga de un nuevo significado, que se entrelaza con esas significaciones ya constituidas (Arribas, 2008). De esta manera, el espacio delimitado al consolidarse como vivienda sigue adquiriendo un carácter de refugio, que toma en consideración todas las funciones aludidas anteriormente e instaura la creación de un nuevo significado para asumirse como lugar donde el individuo puede escapar de los avatares de la cotidianidad para reencontrarse con su esencia.

\section{Referencias}

Agudelo, P. (2011). (Des)hilvanar el sentido/los juegos de Penélope. Una revisión del concepto imaginario y sus implicaciones sociales. Revista UNI_PLURI/VERSIDAD, $11(3)$.

Álvarez, A (marzo 13 de 2016). En 3 años vivirán en Sabaneta 10.000 personas. El colombiano.

Arias, M. (2013). La arquitectura escolar como espacio sociofísico formativo: una mirada desde los/as estudiantes (Tesis de Maestría). Facultad de ciencias sociales Universidad de Chile. Santiago de Chile.

Arribas, S. (2008). Cornelius Castoriadis y el Imaginario Político. Revista Foro Interno: anuario de teoría política, (8), 105-132. Recuperado de http:// revistas. ucm.es/index.php/FOIN/article/viewFile/FOINo808110105A/7870

Calderón, D., David, J. (2013). Las artes plásticas y la representación escénica, una estrategia didáctica para la enseñanza de la literatura infantil. (Tesis de pregrado). Facultad de educación Universidad de Antioquia. Medellín Colombia.

Calvino, I. (1999). Las Ciudades Invisibles. Madrid, España: Ed. de la Maitorial S.A. 
Carlino, P. (2005). La Educación. Documento de trabajo N 19. Escritura en la Investigación. Seminario Permanente de Investigación de la Maestría Escuela de Educación, Universidad de San Andrés.

Castoriadis, C. (1983) La institución imaginaria de la sociedad. Barcelona, España: Tusquets Editores.

Eco, U. (1981) La estructura ausente. Barcelona, España. Editorial Lumen S. A.

Gonzales, N., Quesada, P. (2005). La enseñanza y aprendizaje de la Literatura en complicidad con las Artes Plásticas. Revista Pensamiento Actual, 5(6), 8391. Recuperado de http://revistas.ucr.ac.cr/index.php/pensamiento-actual/article/viewFile/6658/634

Heidegger, M. (1958). Arte y Poesía. México: Editorial Fondo de la Cultura Económica.

Jurado, J. (2003). Ciudad educadora. Aproximaciones contextuales y conceptuales. Estudios Pedagógicos (Valdivia), (29), 127-142. Recuperado de. https:// dx.doi.org/10.4067/So7 18-07052003000100009

Larrosa, J. (2003). La experiencia de la lectura Estudios sobre literatura y formación. México: Fondo de Cultura económica.

López, N. (2009). El papel de las artes plásticas y escénicas en la enseñanza de la literatura. (Trabajo de pregrado). Facultad de educación. Universidad de Antioquía. Medellín, Colombia.

Ministerio de Educación Nacional. (2006). Estándares básicos de competencias del lenguaje. Bogotá, Colombia. Recuperado de http://www.mineducacion. gov.co/cvn/1665/articles-116042_archivo_pdf1.pdf

Muñoz, O. (2003). Construcción narrativa en la historia oral. Bogotá, Colombia: Editorial Nómadas.

Schulz, C. (2008) El pensamiento de Heidegger sobre la arquitectura. Revista Discusiones filosóficas, 9(13) 93-110. Manizales Colombia. Recuperado: http://www.scielo.org.co/scielo.php?script=sci_arttext\&pi$\mathrm{d}=$ So 124-61272008000200006 
Paniagua, E. y Roldan, J. (2015). La arquitectura y su significación existencial. Revista Signa, 24, 443-462. Universidad de Murcia, Universidad Católica San Antonio de Murcia.

Polar, R., Martín, J. (1999). El diario como instrumento para detectar problemas y hacer explícitas las concepciones. En El diario del profesor. Un recurso para la investigación en el aula. Sevilla, España. Díada Editora S. L.

Sennet, R. (1997). Carne y Piedra. El cuerpo y la ciudad en la civilización occidental. Madrid, España: Alianza Editorial.

Vásquez, F. (2008). La escritura y su utilidad en la docencia. Revista Actualidades Pedagógicas, (51), 101-114. Recuperado de: https://revistas.lasalle.edu.co/ index.php/ap/article/viewFile/1354/1238 